\title{
Capability for self-care of patients with heart failure
}

This article was published in the following Dove Press journal:

Clinical Interventions in Aging

\section{Agnieszka Mlynarska ${ }^{1,2}$ \\ Krzysztof S Golba ${ }^{2,3}$ \\ Rafal Mlynarski²}

'Department of Internal Nursing, School of Health Sciences, Medical University of Silesia, Katowice, Poland; ${ }^{2}$ Department of Electrocardiology, Upper Silesian Heart Centre, Katowice, Poland; ${ }^{3}$ Department of Electrocardiology and Heart Failure, School of Health Sciences, Medical University of Silesia, Katowice, Poland
Correspondence: Agnieszka Mlynarska Department of Electrocardiology, Upper Silesian Heart Centre, ul Ziolowa 45/47, Katowice 40-635, Poland

Tel +48322024025

Fax +48 322524098

Email mlynarska83@gmail.com
Background: A thorough analysis of the capability for self-care in patients with heart failure (HF) reduces the frequency of hospitalizations that are caused by decompensation. The aim of the study was to assess the effect of the method of therapy for HF, the degree of the acceptance of illness, and the occurrence of frailty syndrome on adherence to the therapeutic recommendations and self-care in patients with HF.

Methods: The study included 180 patients who were hospitalized after being diagnosed with HF. In all, we used the Polish versions of three validated instruments: the nine-item European Heart Failure Self-care Behavior Scale, Illness Acceptance Scale, and The Tilburg Frailty Indicator. Results: The capability for self-care of patients with HF was $27.8 \%$. More than $65 \%$ of the patients followed the recommendations for taking medication and also followed a low-sodium diet, while only $5.5 \%$ of the patients followed the recommendations for physical exercise. Positive correlations were found between the capability for self-care and frailty syndrome and its components: general frailty components vs the capability for self-care: $r=0.4449, P=0.0000$; physical frailty components vs the capability for self-care: $r=0.3974, P=0.0000$; emotional frailty components vs the capability for self-care: $r=0.2831, P=0.0001$; social frailty components vs the capability for self-care: $r=0.2180, P=0.0032$, and a negative correlation between the capability for self-care and the degree of the acceptance of the illnesses $(r=-0.4662, P=0.0000)$.

Conclusion: A relatively low capability for self-care was found in patients with HF. The presence of frailty syndrome and a low level of the acceptance of illness are connected with a low capability for self-care.

Keywords: self-care, heart failure, frailty, rehospitalization, acceptance of illness

\section{Introduction}

The incidence of heart failure (HF) depends on the definition that is used and applies to $1 \%-2 \%$ of the adult population in developed countries. ${ }^{1} \mathrm{HF}$ is a rapidly growing public health problem that affects at least 26 million people around the world. Despite significant advances in therapy and prevention, mortality and morbidity are still high and the many symptoms associated with HF affect the quality of life of patients. ${ }^{2,3}$ Among the people over 65 years of age who were diagnosed with exercise dyspnea, one-sixth had unrecognized HF. ${ }^{4,5}$ In the group over 70 years, HF affects more than $10 \%$ of the population. ${ }^{6,7}$ The long-term risk of HF symptoms in an individual 55 years of age is $33 \%$ for men and $28 \%$ for women. ${ }^{8}$

In 2003, the World Health Organization (WHO) defined compliance and adherence as the degree to which a patient's behavior (such as taking medication, diet, and lifestyle changes) is consistent with the generally agreed therapeutic recommendations. ${ }^{9}$ The aims of the treatment for patients with HF include improving their clinical status, exercise capacity, and quality of life, preventing hospitalizations and a reduction in total mortality. Although there is little evidence of the impact of specialist advice on lifestyle and quality of life, providing a patient with this information has become a 
major component of educating patients about taking proper care of themselves. Adequate and current information that will allow them to make decisions about lifestyle changes and proper care of themselves should be provided to patients. Ideally, hospitalized patients should get this information before being discharged from the hospital. ${ }^{10}$

A thorough analysis of self-care in individuals with HF reduces the frequency of hospitalizations that are caused by a decompensation of HF. ${ }^{11}$ In the patients with acute HF, compliance with the recommendations is mentioned as the second cause that contributes to the decompensation of chronic HF and that every third hospitalization is due to the exacerbation of HF that is caused by non-compliance with the therapeutic recommendations. ${ }^{12-14}$

In randomized studies on the impact of therapeutic recommendations on rehospitalizations, it has been demonstrated that patients over 70 years of age have a higher risk of rehospitalization. It was also shown that educating patients combined with monitoring the hospital treatment leads to a non-significant reduction in mortality and a significant reduction in the frequency of rehospitalization ( $R R$ 0.56, $P=0.02$ ). Lack of compliance with medical and other lifestyle recommendations is a serious problem in elderly patients who suffer from HF and have serious consequences for individual patients and their families as well as for the health care system. ${ }^{15,16}$

The frailty syndrome is an indicator of biological age. Patients with a diagnosed frailty syndrome are more likely to have reduced ability to perform basic activities of daily living, more frequent hospitalizations, and death. Early diagnosis is crucial for improving the course of the disease and the self-care.

The aim of the study was to assess the effect of the method of the therapy for HF, the degree of the acceptance of illness, and the occurrence of frailty syndrome on adherence to the therapeutic recommendations and self-care in patients with HF.

\section{Methods}

The study included 196 consecutive patients who were hospitalized in the Department of Electrocardiology and Heart Failure of the Medical University of Silesia between January 2015 and June 2016 and who had been diagnosed with HF.

\section{Eligibility criteria}

The patients included in the study had to meet the following inclusion criteria: diagnosed with HF at least 6 months earlier, consent to participate in the study, and being more than 60 years of age.
Exclusion criteria included patients with chronic renal failure, ischemic or hemorrhagic stroke over a period of 6 months, and severe dementia, which would make it impossible for the individual to answer the questions in the assessment of compliance with the recommendations, the assessment of the acceptance of illness, and the identification of frailty syndrome.

Finally, 180 patients were included in the study; eleven patients did not fill in the questionnaire completely (lack of answers to all the questions) and five withdrew their consent to participate in the study because of scheduled follow-up visits.

\section{Study design}

Patients were included in the study by a cardiology nurse after the presentation of the purpose and principles of the study and receiving their consent to participate in the study. A physical examination, anthropometric examination, and laboratory tests were additionally performed in all of the individuals who were included in the study. The treatment for HF was verified and the optimal therapy (pharmacological or device-based) was confirmed in all of the participants. Depending on the treatment that was being used, the patients were divided into three groups:

1. Group I: HF being treated conservatively by pharmacological treatment and lifestyle changes (treated conservatively), 51 patients $(28.33 \%)$

2. Group II: HF being treated with the implantation of a cardioverter-defibrillator (ICD), 47 patients $(26.11 \%)$

3. Group III: HF being treated with the implantation of a cardiac resynchronization system (CRT), 82 patients $(45.56 \%)$

\section{Ethical consideration}

The local ethics committee of the Medical University of Silesia approved the study protocol (approval no KNW/0022/ KB1/238/16). The study protocol complied with the version of the Helsinki Convention that was current at the time the study was designed. ${ }^{17}$

\section{Psychometric tools used in the research}

In all of the patients that were included in the study, we used the Polish version of three validated instruments: the nineitem European Heart Failure Self-care Behavior Scale (EHFScBS-9), Acceptance of Illness Scale (AIS), and The Tilburg Frailty Indicator (TFI).

The EHFScBS-9 scale contains nine statements regarding the level of self-care of patients with HF; five statements concern self-care, while the next four concern 
the assessment of the level of symptom reporting which could indicate disease progression to a doctor or nurse. Answers to the statements are given on the Likert-based scale, where one point means "I completely agree" and five points mean "I do not agree at all". The result is obtained by adding up the number of points; the more the points, the worse is the capability for self-care. A mean value of 1 or 2 on the Likert scale indicates a high or satisfactory level of self-care. To facilitate the interpretation of results and to be able to handle them with another self-care assessment tool described in the literature, the overall level of self-care has been transformed to the 1-100 scale proposed by Vellone et al. ${ }^{33}$ The EHFScBS-9 scale that was adapted to Polish conditions by Uchmanowicz has a reliability of alpha $=0.787$, which means that the scale is characterized by a good reliability index. ${ }^{18}$

In the present study, a standardized tool to assess the acceptance of illness (AIS), which was adapted to Polish conditions by Jurczyński, was also used. The scale contains eight statements that describe the negative consequences of a poor health condition. Responses are given on the five-point Likert-based scale, where one means "a poor adaptation to the disease" and five means "the full acceptance of illness". The sum of points is in the range of 8-40; the more points that are obtained, the better is the degree of acceptance of the illness. In addition, the results can be assigned to three groups depending on the degree of acceptance of the illness: a lack of acceptance of the illness (8-18 points), moderate acceptance of the illness (19-29 points), and a high acceptance of the illness (30-40 points). ${ }^{19}$

TFI scale was used to evaluate frailty. This scale consists of two parts: the first part deals with the factors that determine the frailty syndrome and the second part contains 15 questions that are related to the main components of frailty. The minimum number of points from the questionnaire is 0 and the maximum is 15 points. A score of 5 or more points indicates the occurrence of frailty syndrome. ${ }^{20}$

\section{Primary and secondary end points}

The primary end point was the impact of frailty syndrome, the acceptance of the illness, and the treatment method on the capability for self-care. The secondary end point was the effects of the capability for self-care on rehospitalization. Rehospitalization was defined as hospital admission due to cardiovascular causes self-recorded by the patients.

\section{Statistical analysis}

The data that were obtained were analyzed statistically, and the values were treated as significant when $P<0.05$.
The results that were obtained from the evaluation of the capability for self-care and frailty syndrome using the TFI and the assessment of the acceptance of illness using the AIS are presented as the arithmetic mean with the corresponding SD. The Student's $t$-test was used to compare the quantitative data with a normal distribution and the chi-squared test was used for the non-parametric data. The Kruskal-Wallis was used to compare the values for more than two groups. The Pearson correlation coefficient $r$ was used to correlate the EHFScBS-9 scale with the level of the acceptance of the illness and frailty. The diagnostic utility of the EHFScBS-9 scale in separating patients that were more exposed to rehospitalization was determined using the receiver-operating characteristic (ROC) curves. The results are expressed in terms of the area under the curve and the $95 \% \mathrm{CI}$ for this area. The survival curve for time to end point - rehospitalization for HF - was calculated and is presented using the KaplanMeier method. All of the calculations were performed using MedCalc.

\section{Results}

One hundred eighty patients (mean age $72.77 \pm 7.98$ years) diagnosed with HF were included in the study; among them, $29.4 \%$ were women. The characteristics of the patients that were included in the study are presented in Table 1 . The mean follow-up time was 454.6 \pm 262.1 days. During observation, two patients died - one from group II and one from group III. It was necessary to rehospitalize 40 patients - $36(70.59 \%)$ from group I, two (4.25\%) from group II, and one (1.22\%) from group III.

\section{Capability for self-care}

A satisfactory or good level of the capability for self-care of patients with HF was found in $27.8 \%$ of the patients. More than $65 \%$ of the patients followed the recommendations for taking medication and $41.66 \%$ used a low-sodium diet, while only $5.5 \%$ of the patients followed the recommendations for physical exercise. The average value of the level of the capability for self-care of patients was $27.74 \pm 5.25$ points, and the best-observed capability for self-care was among the following variables: "I take my medication as prescribed"

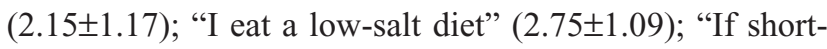
ness of breath increases, I contact my doctor or nurse" $(2.99 \pm 0.84)$, while the least-observed variable of self-care was "I exercise regularly" (4.08 \pm 0.96$)$.

Analysis of the degree of the capability for self-care depending on the treatment that was used (conservative, ICD, CRT) is shown in Table 2. Statistically significant differences in the capability for self-care in the variabilities for contact 
Table I Characteristics of the patients that were included in the study

\begin{tabular}{|c|c|c|c|c|c|}
\hline Variable & All patients & Group I, n=5 I & Group II, n=47 & Group III, $n=82$ & $P$-value \\
\hline Age, years & $72.77 \pm 7.98$ & $75.65 \pm 8.6$ & $70.62 \pm 8.02$ & $72.21 \pm 7.09$ & 0.0112 \\
\hline Gender [female \%] & $29.44 \%$ & $41.18 \%$ & $14.89 \%$ & 30.49 & 0.0165 \\
\hline Ejection fraction [mean $\pm \mathrm{SD}$, \%] & $33.88 \pm 12.33$ & $41.96 \pm 14.54$ & $29.72 \pm 8.39$ & $31.19 \pm 10.32$ & 0.0000 \\
\hline Atrial fibrillation [\%] & 49.44 & 52.94 & 46.81 & 48.78 & 0.8208 \\
\hline Body mass index & $29.99 \pm 5.74$ & $30.07 \pm 5.07$ & $29.52 \pm 5.23$ & $30.32 \pm 10.94$ & 0.2749 \\
\hline Hypertension [\%] & 83.88 & 76.47 & 91.49 & 84.15 & 0.2169 \\
\hline Diabetes [\%] & 42.78 & 45.09 & 38.29 & 43.90 & 0.7634 \\
\hline Sinus node dysfunction [\%] & 17.78 & 31.37 & 8.51 & 14.63 & 0.0076 \\
\hline Atrioventricular block [\%] & 25.55 & 27.45 & 14.89 & 39.49 & 0.1385 \\
\hline Myocardial infarction [\%] & 70.00 & 60.78 & 80.85 & 69.51 & 0.0951 \\
\hline Frailty syndrome & $5.29 \pm 2.42$ & $5.16 \pm 2.72$ & $5.34 \pm 2.44$ & $5.34 \pm 2.23$ & 0.8309 \\
\hline The acceptance of illness scale [AIS] & $27.74 \pm 5.25$ & $29.98 \pm 5.27$ & $27.19 \pm 2.44$ & $26.67 \pm 4.4$ & 0.0035 \\
\hline Overall level of self-care & $26.84 \pm 4.08$ & $26.69 \pm 4.43$ & $27.17 \pm 3.9$ & $26.76 \pm 3.99$ & 0.7031 \\
\hline
\end{tabular}

Notes: Group I - heart failure treated conservatively; Group II - heart failure treated with the implantation of a cardioverter-defibrillator; Group III - heart failure treated with the implantation of a resynchronization system.

with a doctor or nurse due to dyspnea $(P=0.0317)$, weight gain by $2 \mathrm{~kg}$ in 7 days $(P=0.0164)$, as well as restrictions on fluid intake $(P=0.0224)$ and following a salt-free diet and physical activity $(P=0.0124 ; P=0.0010)$ were found. It was shown that patients undergoing conservative treatment had a lower capability for self-care compared to those who were treated with cardiac resynchronization.

\section{Influence of the acceptance of illnesses on the capability for self-care}

The analysis of the influence of the degree of the acceptance of the illnesses on the capability for self-care shows that the lower the patient's acceptance level, the worse is their capability for self-care. There were statistically significant differences in the capability for self-care depending on the assessment of the acceptance of illness in all of the questions except for the variable "I exercise regularly" $(P=0.1518)$. Detailed data are presented in Table 3.

\section{Correlations}

The correlations between the capability for self-care with the degree of the acceptance of the illness and the occurrence of frailty syndrome were also assessed. Positive correlations were found between the capability for self-care and frailty syndrome and its components: general frailty vs the capability for self-care: $r=0.4449, P=0.0000$; physical

Table 2 Degree of the capability for self-care depending on the treatment

\begin{tabular}{|c|c|c|c|c|}
\hline EHFScBS-9 & Group I, n=5 I & Group II, n=47 & Group III, n=82 & $P$-value \\
\hline I weigh myself every day & $3.37 \pm 0.77$ & $3.15 \pm 0.75$ & $3.07 \pm 0.69$ & 0.0546 \\
\hline If shortness of breath increases, I contact my doctor or nurse & $3.25 \pm 0.82$ & $2.91 \pm 0.93$ & $2.86 \pm 0.76$ & 0.0317 \\
\hline If legs/feet are more swollen, I contact my doctor or nurse & $3.4 I \pm 0.87$ & $3.08 \pm 0.75$ & $3.09 \pm 0.68$ & 0.0626 \\
\hline If I gain weight more than $2 \mathrm{~kg}$ in 7 days, I contact my doctor or nurse & $3.57 \pm 0.85$ & $3.28 \pm 0.83$ & $3.11 \pm 0.82$ & 0.0164 \\
\hline I limit the amount of fluids (not more than I.5-2 liters a day) & $3.29 \pm 0.96$ & $2.87 \pm 0.82$ & $2.89 \pm 0.84$ & 0.0224 \\
\hline If I experience fatigue, I contact my doctor or nurse & $3.25 \pm 0.87$ & $3.17 \pm 0.76$ & $3.02 \pm 0.86$ & 0.3195 \\
\hline I eat a low-salt diet & $3.12 \pm 1.18$ & $2.48 \pm 0.99$ & $2.67 \pm 1.03$ & 0.0124 \\
\hline I take my medication as prescribed & $2.33 \pm 1.19$ & $2.00 \pm 1.12$ & $2.13 \pm 1.13$ & 0.2566 \\
\hline I exercise regularly & $4.37 \pm 0.87$ & $4.23 \pm 0.89$ & $3.82 \pm 0.98$ & 0.0010 \\
\hline Overall level of self-care & $29.98 \pm 5.72$ & $27.19 \pm 5.43$ & $26.67 \pm 4.41$ & 0.0035 \\
\hline Overall level of self-care on a $0-100$ scale & $39.87 \pm 16.69$ & $54.37 \pm 14.23$ & $49.99 \pm 11.64$ & 0.0003 \\
\hline
\end{tabular}

Notes: Group I - heart failure treated conservatively; Group II - heart failure treated with the implantation of a cardioverter-defibrillator; Group III - heart failure treated with the implantation of a resynchronization system. Bold values indicate significance $<0.05$.

Abbreviation: EHFScBS-9, nine-item European Heart Failure Self-care Behavior Scale. 
Table 3 Influence of the degree of the acceptance of the illnesses on the capability for self-care

\begin{tabular}{|c|c|c|c|c|}
\hline \multirow[t]{2}{*}{ EHFScBS-9 } & \multicolumn{3}{|c|}{ Acceptance of illness } & \multirow[t]{2}{*}{$P$-value } \\
\hline & High, $n=5$ I & Moderate, $n=|2|$ & Low, $n=8$ & \\
\hline I weigh myself every day & $2.88 \pm 0.76$ & $3.24 \pm 0.67$ & $4.12 \pm 0.6$ & 0.0001 \\
\hline If shortness of breath increases, I contact my doctor or nurse & $2.86 \pm 0.87$ & $2.97 \pm 0.75$ & $4.00 \pm 0.75$ & 0.0427 \\
\hline If legs/feet are more swollen, I contact my doctor or nurse & $2.98 \pm 0.76$ & $3.21 \pm 0.74$ & $4.00 \pm 0.75$ & 0.0013 \\
\hline If I gain weight more than $2 \mathrm{~kg}$ in 7 days, I contact my doctor or nurse & $3.02 \pm 0.81$ & $3.34 \pm 0.83$ & 4. $12 \pm 0.64$ & 0.0071 \\
\hline I limit the amount of fluids (not more than I.5-2 liters a day) & $2.72 \pm 0.83$ & $3.03 \pm 0.85$ & $4.12 \pm 0.83$ & 0.0004 \\
\hline If I experience fatigue, I contact my doctor or nurse & $2.96 \pm 0.85$ & $3.1 \pm 0.82$ & $4.00 \pm 0.53$ & 0.1039 \\
\hline I eat a low-salt diet & $2.43 \pm 1,06$ & $2.83 \pm 1.08$ & $3.62 \pm 0,74$ & 0.0001 \\
\hline I take my medication as prescribed & $1.91 \pm 1.08$ & $2.21 \pm 1.13$ & $3.00 \pm 1.85$ & 0.0002 \\
\hline I exercise regularly & $3.784 \pm 1.06$ & $4.16 \pm 0.88$ & $4.75 \pm 0.46$ & 0.1518 \\
\hline Overall level of self-care & $25.55 \pm 5.27$ & $28.14 \pm 4.65$ & $35.75 \pm 5.01$ & 0.0000 \\
\hline Overall level of self-care on a $0-100$ scale & $53.82 \pm 8.12$ & $51.44 \pm 13.02$ & $39.87 \pm 16.69$ & 0.0643 \\
\hline
\end{tabular}

Abbreviation: EHFScBS-9, nine-item European Heart Failure Self-care Behavior Scale.

frailty components vs the capability for self-care: $r=0.3974$, $P=0.0000$; emotional frailty components vs the capability for self-care: $r=0.2831, P=0.0001$; social frailty components vs the capability for self-care: $r=0.2180, P=0.0032$, and a negative correlation between the capability for self-care and the degree of the acceptance of the illnesses $(r=-0.4662$, $P=0.0000$ ). These correlations, which were divided into groups according to the types of treatment, are presented in Table 4. In addition, self-care was also influenced by the age ( $r=0.1964, P=0.0082)$.

\section{Risk of rehospitalization analysis}

The level of the capability for self-care in patients with HF has been described as an additional risk factor for rehospitalization. The EHFScBS-9, which has a cutoff value of $>28$ points, identified patients that had a significantly higher risk of rehospitalization for HF. Analysis of the impact of the capability for self-care on rehospitalization revealed that in the group of patients that were treated conservatively, the cutoff point was $\leq 30$ points ( $P=0.1738$ ), in the group of patients that were treated with ICD $>32$ points $(P=0.0001)$ and in the group of patients that were treated with CRT were $>28$ points $(P=0.0394)$. The lower cutoff level for patients with implanted CRT seems to be clinically significant. It concerns the group of the most burdened patients, and despite the fact that it was the group that showed the best capability for self-care, it was the one that was most frequently rehospitalized. Their cutoff point was the lowest, which means that despite their capability for self-care, these patients are particularly vulnerable to rehospitalization and should be under special supervision in a long-term observation. The ROC curves are presented graphically in Figure 1.

\section{Survival curves for time to rehospitalization due to $\mathrm{HF}$}

Analysis of the influence of the components of self-care on possible rehospitalization due to cardiovascular issues did

Table 4 Correlation between the level of self-care and frailty syndrome and its components as well as the degree of the acceptance of the illnesses depending on the treatment

\begin{tabular}{|c|c|c|c|c|c|}
\hline Group & $\begin{array}{l}\text { Frailty } \\
\text { general }\end{array}$ & $\begin{array}{l}\text { Frailty physical } \\
\text { components }\end{array}$ & $\begin{array}{l}\text { Frailty emotional } \\
\text { components }\end{array}$ & $\begin{array}{l}\text { Frailty social } \\
\text { components }\end{array}$ & $\begin{array}{l}\text { Acceptance of } \\
\text { the illnesses }\end{array}$ \\
\hline Group I & $\begin{array}{l}r=0.4223 \\
P=0.0020\end{array}$ & $\begin{array}{l}r=0.2637 \\
P=0.0615\end{array}$ & $\begin{array}{l}r=0.4845 \\
P=0.0003\end{array}$ & $\begin{array}{l}r=0.3412 \\
P=0.0143\end{array}$ & $\begin{array}{l}r=-0.3969 \\
P=0.0039\end{array}$ \\
\hline Group II & $\begin{array}{l}r=0.3963 \\
P=0.0002\end{array}$ & $\begin{array}{l}r=0.4596 \\
P=0.000 I\end{array}$ & $\begin{array}{l}r=0.0931 \\
P=0.4055\end{array}$ & $\begin{array}{l}r=0.124 I \\
P=0.2665\end{array}$ & $\begin{array}{l}r=-0.4682 \\
P=0.0001\end{array}$ \\
\hline Group III & $\begin{array}{l}r=0.6367 \\
P=0.0001\end{array}$ & $\begin{array}{l}r=0.5720 \\
P=0.000 I\end{array}$ & $\begin{array}{l}r=0.3941 \\
P=0.0061\end{array}$ & $\begin{array}{l}r=0.2059 \\
P=0.1649\end{array}$ & $\begin{array}{l}r=-0.6133 \\
P=0.0001\end{array}$ \\
\hline
\end{tabular}

Notes: Group I - heart failure treated conservatively; Group II - heart failure treated with the implantation of a cardioverter-defibrillator; Group III - heart failure treated with the implantation of a resynchronization system. 

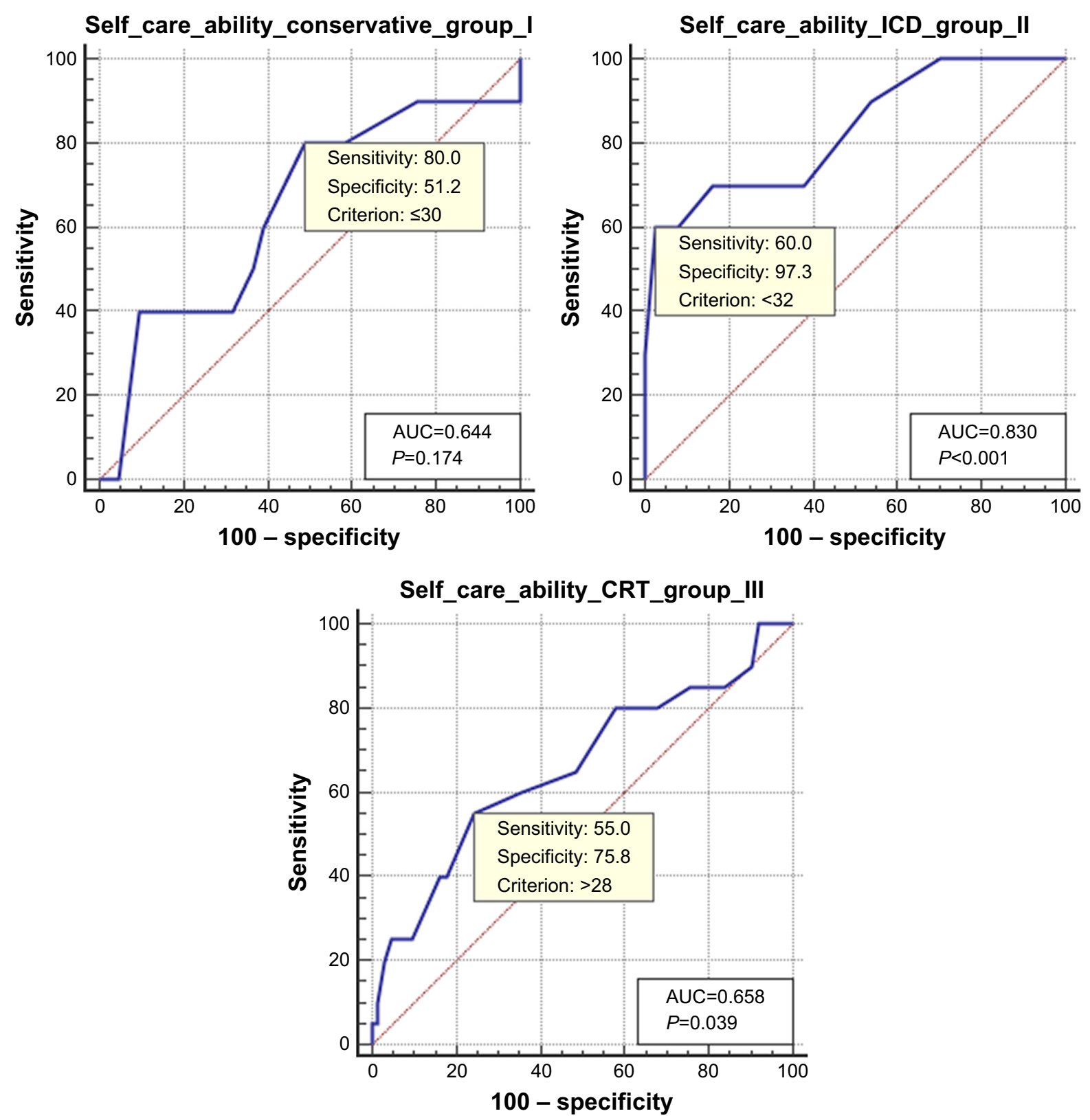

Figure I Characteristic curves of the EHFScBS-9 score to predict hospitalization.

Notes: Group I - heart failure treated conservatively; Group II - heart failure treated with the implantation of a cardioverter-defibrillator; Group III - heart failure treated with the implantation of a resynchronization system.

Abbreviations: AUC, area under the curve; FScBS-9, nine-item European Heart Failure Self-care Behavior Scale; ICD, implantable cardioverter-defibrillator.

not show statistically significant differences in the overall population. However, it was demonstrated that for patients with an implanted ICD and for patients with an implanted CRT, compliance with the recommendations influenced the frequency of rehospitalizations. In the patients with HF who were treated with conservative treatment, the contribution of the components to rehospitalization was not demonstrated. The details are presented in Figure 2.

\section{Discussion}

According to the presented results, patients undergoing conservative treatment had a lower capability for self-care compared with those who were treated invasively (cardiac resynchronization). Non-pharmacological treatment management may significantly impact a patient's physical functioning and emotional status, rehospitalization, mortality, and quality of life. The most important non-pharmacological recommendations for patients with diagnosed HF are restricting the sodium in their diet, restricting fluid intake, detecting signs of decompensation, and doing physical activities. Studies on the adherence to therapeutic recommendations in older patients with $\mathrm{HF}$ revealed the adherence rate ranges between $10 \%$ and $99 \%$ depending on the instrument that is used in the assessment. ${ }^{21,22}$ Schwarz et al showed a 

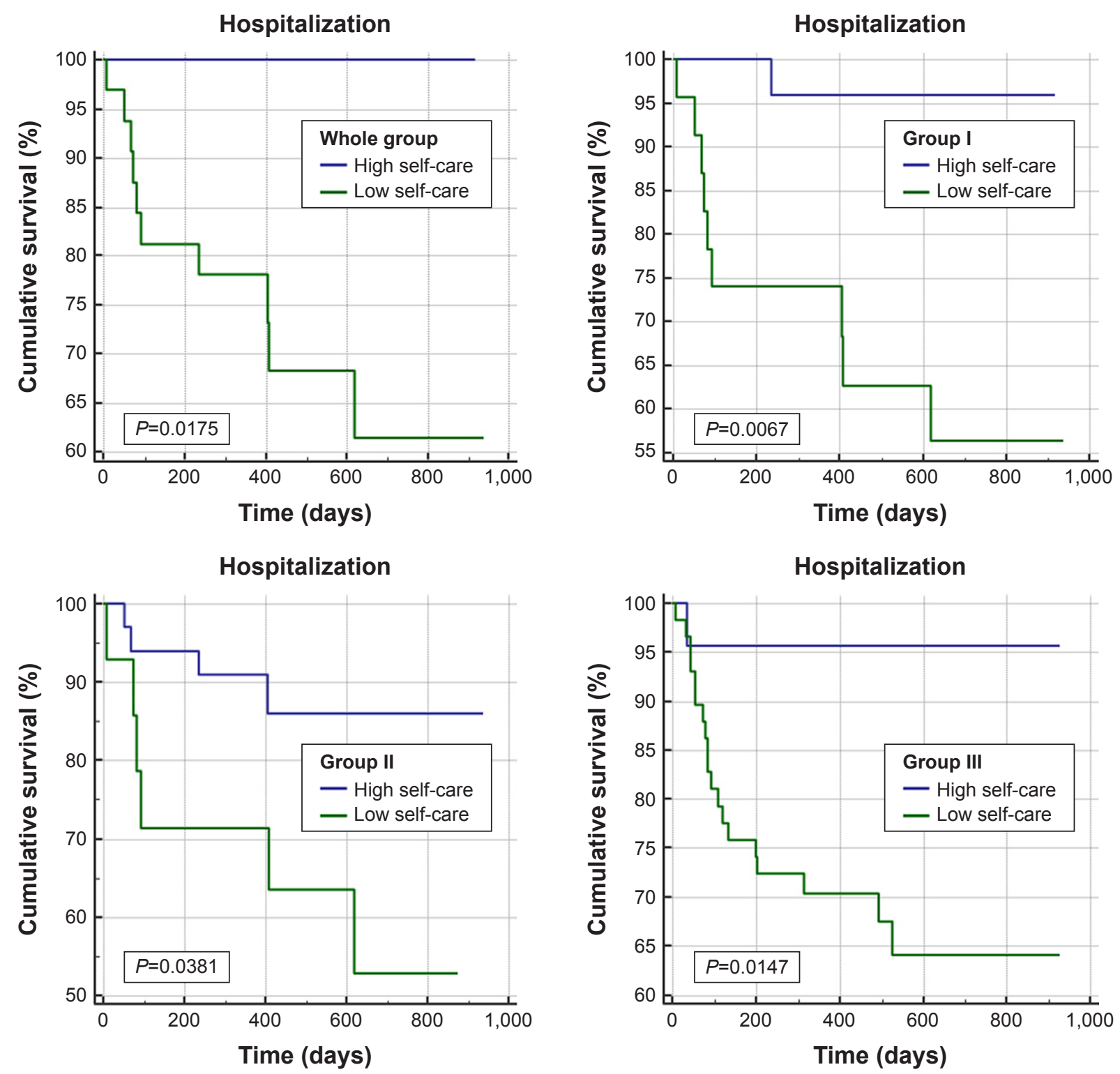

Figure 2 Survival curves for time to end point - rehospitalization for HF.

Notes: Group I - heart failure treated conservatively; Group II - heart failure treated with the implantation of a cardioverter-defibrillator; Group III - heart failure treated with the implantation of a resynchronization system.

99\% compliance, while Monane et al showed only a $10 \%$ compliance. Such large discrepancies in the adherence to recommendations are related to the number of factors that affect compliance..$^{23,24}$

The average value of the capability for self-care in the present study was 27.74 points, which is a result similar to that presented by Uchmanowicz et al (27.65 points). An analysis showed that observance of the recommendations regarding limited fluid consumption, following a low-salt diet, and using medications as prescribed were the best adherence recommendations. The same results were obtained by Uchmanowicz et al; however, the results presented in those studies refer to patients with HF that were treated without using implantable devices. In our study, the group of patients that were treated conservatively had a much worse compliance with the therapeutic recommendations. ${ }^{18}$ The literature states that only $80 \%$ of patients were taking a new medication at discharge, 1 month after hospitalization, and in the following months, and the percentage of people taking these medications dropped to $60 \%$ and continued at this level for a year. ${ }^{25}$ Only $34 \%$ of patients discharged from the hospital after a HF decompensation event take medication according to the directions on the discharge instructions. ${ }^{26}$

Failure to comply with therapeutic recommendations may have a significant impact on the health of patients with HF. In the $\mathrm{COACH}$ (Coordinating survey evaluating Outcomes of Advising and Counseling in Heart Failure) study conducted 
by Wal et al on a group of 830 patients, it was demonstrated that patients who adhered to all of the therapeutic recommendations, i.e., daily weight control, regular physical activity, and limiting salt and fluid intake achieved a statistically significant reduction in the risk of rehospitalizations due to an exacerbation of HF. However, if the exacerbation did require hospitalization, the period of hospitalization was shorter than in non-compliant patients.

The fewer recommendations the patients adhered to, the more often they were rehospitalized or died because of HF. More than half of the patients did not comply with any recommendation. Our research showed that $27.9 \%$ of patients had good or satisfactory compliance independent from the study group. In the COACH study, $90 \%$ of the patients stated that they restricted their intake of sodium and fluids, while in our study $41.66 \%$ of the patients stated that they followed a low-sodium diet. In our study $60 \%$ said they performed regular physical activity, but only $5.5 \%$ of the patients said that they performed a good or satisfactory level of exercise. It was shown that the lack of daily physical activity and regular weight control was associated with more frequent rehospitalizations. ${ }^{27} \mathrm{Wu}$ et al showed that patients who complied with the therapeutic recommendations for the treatment of HF had less frequent exacerbations of the disease and rehospitalizations compared to patients who did not comply with the therapeutic recommendations. ${ }^{28}$

In the study of Dunbar et al, social support from family and friends resulted in better adherence in patients with HF. The results of our study show that frailty syndrome in the social component results in a deterioration in the capability for self-care as well as compliance with the therapeutic recommendations. ${ }^{29}$

Among the factors that contribute to the deterioration of health, the most common are associated diseases, noncompliance with the therapeutic recommendations, lack of self-control, and lack of optimal treatment. ${ }^{30}$ Anemma et al stated in their research that $23 \%-31 \%$ of rehospitalizations could be avoided if the recommendations were more respected and the patients had access and the opportunity to cooperate with a suitably prepared multidisciplinary team. Nursing intervention might also positively influence the capability for self-care. ${ }^{31}$

In their study, Aggarwal et al showed that compliance and self-care varied depending on the therapy and that the results that were obtained in the conservatively treated population should not be applied to patients that are treated with antiarrhythmic devices. In our study on compliance with medical recommendations, the method of treatment had an influence.
The patients that were treated conservatively had the worst compliance with medical recommendations compared to the patients that were treated with anti-arrhythmic devices. Additionally, compliance with the therapeutic recommendations was influenced by the occurrence of frailty syndrome, the degree of acceptance of illness, age, and the severity of the symptoms of $\mathrm{HF}^{32}$

\section{Study limitation}

The study presented here had a few limitations. This was a single-center study, and a relatively small number of patients were recruited into the individual groups at one center. Selfcare and adherence to the recommendations were evaluated using a questionnaire that relies on the patient's self-assessment of the application of the recommendations, and therefore there may be limitations that are related to an excessive overestimation or underestimation of compliance.

\section{Conclusion}

A relatively low capability for self-care in patients with HF was found. Following the recommendation for physical exercise is the biggest problem as opposed to compliance with a low-sodium diet and taking medication. The method of treatment that is chosen for the patient also affects the capability for self-care - cardiac resynchronization is connected with the best level of the capability for self-care. We believe that this may be connected with the more excessive education and strict cooperation with therapeutic team in the CRT group. The presence of frailty syndrome and a low level of the acceptance of the illness are connected with low level of capability for self-care.

\section{Acknowledgment}

This project was funded by the Medical University of Silesia (grant KNW-2-Z13/N/7/N).

\section{Disclosure}

The authors report no conflicts of interest in this work.

\section{References}

1. Ponikowski P, Voors AA, Anker SD, et al; ESC Scientific Document Group. 2016 ESC Guidelines for the diagnosis and treatment of acute and chronic heart failure: The Task Force for the diagnosis and treatment of acute and chronic heart failure of the European Society of Cardiology (ESC). Developed with the special contribution of the Heart Failure Association (HFA) of the ESC. Eur J Heart Fail. 2016;37(27):2129-2200.

2. Savarese G, Lund LH. Global Public Health Burden of Heart Failure. Card Fail Rev. 2017;3(1):7-11.

3. Ziaeian B, Fonarow GC. Epidemiology and aetiology of heart failure. Nat Rev Cardiol. 2016;13(6):368-378. 
4. van Riet EE, Hoes AW, Limburg A, Landman MA, van der Hoeven H, Rutten FH. Prevalence of unrecognized heart failure in older persons with shortness of breath on exertion. Eur J Heart Fail. 2014;16(7): 772-777.

5. Filippatos G, Parissis JT. Heart failure diagnosis and prognosis in the elderly: the proof of the pudding is in the eating. Eur J Heart Fail. 2011;13(5):467-471.

6. Mosterd A, Hoes AW. Clinical epidemiology of heart failure. Heart. 2007;93(9):1137-1146.

7. Redfield MM, Jacobsen SJ, Burnett JC, Mahoney DW, Bailey KR, Rodeheffer RJ. Burden of systolic and diastolic ventricular dysfunction in the community: appreciating the scope of the heart failure epidemic. JAMA. 2003;289(2):194-202.

8. Bleumink GS, Knetsch AM, Sturkenboom MC, et al. Quantifying the heart failure epidemic: prevalence, incidence rate, lifetime risk and prognosis of heart failure The Rotterdam Study. Eur Heart J. 2004; 25(18):1614-1619.

9. Burkhart PV, Sabaté E. Adherence to long-term therapies: evidence for action. J Nurs Scholarsh. 2003;35(3):207.

10. Jovicic A, Holroyd-Leduc JM, Straus SE. Effects of self-management intervention on health outcomes of patients with heart failure: a systematic review of randomized controlled trials. BMC Cardiovasc Disord. 2006;6:43.

11. Mcalister FA, Stewart S, Ferrua S, Mcmurray JJ. Multidisciplinary strategies for the management of heart failure patients at high risk for admission: a systematic review of randomized trials. $\mathrm{J} \mathrm{Am} \mathrm{Coll} \mathrm{Cardiol}$. 2004;44(4):810-819.

12. Nieminen MS, Brutsaert D, Dickstein K, et al; EuroHeart Survey Investigators; Heart Failure Association, European Society of Cardiology. EuroHeart Failure Survey II (EHFS II): a survey on hospitalized acute heart failure patients: description of population. Eur Heart J. 2006; 27(22):2725-2736.

13. Lycholip E, Thon Aamodt I, Lie I, et al. The dynamics of self-care in the course of heart failure management: data from the IN TOUCH study. Patient Prefer Adherence. 2018;12:1113-1122.

14. Wonggom $\mathrm{P}$, du H, Clark RA. Evaluation of the effectiveness of an interactive avatar-based education application for improving heart failure patients' knowledge and self-care behaviours: A pragmatic randomized controlled trial protocol. J Adv Nurs. Epub 2018 Jun 19.

15. Rich MW, Beckham V, Wittenberg C, et al. A multidisciplinary intervention to prevent the readmission of elderly patients with congestive heart failure. N Engl J Med. 1995;333(18):1190-1195.

16. da Conceição AP, dos Santos MA, dos Santos B, da Cruz Dde A. Self-care in heart failure patients. Rev Lat Am Enfermagem. 2015;23(4):578-586 [Article in English, Portuguese, Spanish].

17. World Medical Association. World Medical Association Declaration of Helsinki: ethical principles for medical research involving human subjects. JAMA. 2013;310(20):2191-2194.

18. Uchmanowicz I, Wleklik M. Polish adaptation and reliability testing of the nine-item European Heart Failure Self-care Behaviour Scale (9-EHFScBS). Kardiol Pol. 2016;74(7):691-696.

19. Felton BJ, Revension TA, Hionrichsen GA. Skala akceptacji choroby AIS [The Acceptance of Illness Scale]. In: Juczynski Z, editor. Narzędzia pomiaru $w$ promocji zdrowia I psychoonkologii zdrowia. Warsaw: Pracownia testów psychologicznych; 2009:162-166. Polish.
20. Uchmanowicz I, Jankowska-Polańska B, Łoboz-Rudnicka M, Manulik S, Łoboz-Grudzień K, Gobbens RJ. Cross-cultural adaptation and reliability testing of the Tilburg Frailty Indicator for optimizing care of Polish patients with frailty syndrome. Clin Interv Aging. 2014; 9:997-1001.

21. van der Wal MH, Jaarsma T, van Veldhuisen DJ. Non-compliance in patients with heart failure; how can we manage it? Eur J Heart Fail. 2005;7(1):5-17.

22. van der Wal MH, Jaarsma T. Adherence in heart failure in the elderly: problem and possible solutions. Int J Cardiol. 2008;125(2):203-208.

23. Monane M, Bohn RL, Gurwitz JH, Glynn RJ, Avorn J. Noncompliance with congestive heart failure therapy in the elderly. Arch Intern Med. 1994;154(4):433-437.

24. Schwarz KA, Elman CS. Identification of factors predictive of hospital readmissions for patients with heart failure. Heart Lung. 2003; 32(2):88-99.

25. Moser DK, Doering LV, Chung ML. Vulnerabilities of patients recovering from an exacerbation of chronic heart failure. Am Heart $J$ 2005;150(5):984.

26. Butler J, Arbogast PG, Daugherty J, Jain MK, Ray WA, Griffin MR. Outpatient utilization of angiotensin-converting enzyme inhibitors among heart failure patients after hospital discharge. J Am Coll Cardiol. 2004;43(11):2036-2043.

27. van der Wal MH, van Veldhuisen DJ, Veeger NJ, Rutten FH, Jaarsma T. Compliance with non-pharmacological recommendations and outcome in heart failure patients. Eur Heart J. 2010;31(12):1486-1493.

28. Wu JR, Moser DK, Chung ML, Lennie TA. Objectively measured, but not self-reported, medication adherence independently predicts eventfree survival in patients with heart failure. J Card Fail. 2008;14(3) 203-210.

29. Dunbar SB, Clark PC, Quinn C, Gary RA, Kaslow NJ. Family influences on heart failure self-care and outcomes. J Cardiovasc Nurs. 2008;23(3):258-265.

30. O'Connor CM, Miller AB, Blair JE, et al; Efficacy of Vasopressin Antagonism in heart Failure Outcome Study with Tolvaptan (EVEREST) investigators. Causes of death and rehospitalization in patients hospitalized with worsening heart failure and reduced left ventricular ejection fraction: results from Efficacy of Vasopressin Antagonism in Heart Failure Outcome Study with Tolvaptan (EVEREST) program. Am Heart J. 2010;159(5):841.e1-849.e1.

31. Annema C, Luttik ML, Jaarsma T. Reasons for readmission in heart failure: Perspectives of patients, caregivers, cardiologists, and heart failure nurses. Heart Lung. 2009;38(5):427-434.

32. Aggarwal B, Pender A, Mosca L, Mochari-Greenberger H. Factors associated with medication adherence among heart failure patients and their caregivers. J Nurs Educ Pract. 2015;5(3):22-27.

33. Vellone E, Jaarsma T, Strömberg A, et al. The European Heart Failure Self-care Behaviour Scale: new insights into factorial structure reliability, precision and scoring procedure. Patient Educ Couns 2014;94:97-102.
Clinical Interventions in Aging

\section{Publish your work in this journal}

Clinical Interventions in Aging is an international, peer-reviewed journal focusing on evidence-based reports on the value or lack thereof of treatments intended to prevent or delay the onset of maladaptive correlates of aging in human beings. This journal is indexed on PubMed Central, MedLine,

\section{Dovepress}

CAS, Scopus and the Elsevier Bibliographic databases. The manuscript management system is completely online and includes a very quick and fair peer-review system, which is all easy to use. Visit http://www.dovepress. com/testimonials.php to read real quotes from published authors. 